\title{
Research on Watson' Theory of Human Nature Care and Its Application Status
}

\author{
Shuang LIU \\ School of Nursing, Beihua University \\ Jilin province, Jilin City, China, \\ 774520609@qq.com
}

\author{
Jihong WANG \\ School of Nursing, Beihua University \\ Jilin province, Jilin City, China, \\ jlwjh@sohu.com
}

\begin{abstract}
This paper explored the research and application status of Watson's theory of human nature care at home and abroad. The paper analyzed and summarized the literature on Watson's theory of human nature care at home and abroad from June 2004 to June 2018. Watson's theory of human nature care has become a hot topic in clinical research, which plays an important role in guiding patients' psychological care, promoting disease rehabilitation and improving patients' satisfaction and also provides a reliable theoretical basis for encouraging patients to respond positively to diseases.
\end{abstract}

Keywords-Watson; The theory of human nature care; Nursing Application status

\section{INTRODUCTION}

Human caring is also called human concern and love. Human caring theory was founded (in 1979), published and revised (in 1985) by the senior nursing theorist Professor Watson of the School of Nursing at the University of Colorado, USA. She proposed that "human caring is the essence of nursing" and extended the nursing science to the development stage of human caring based on "caring the life and health of the whole human"[1]. Watson's nursing theory was refined from the theories and practices of other theorists, including the theory of Nightingale, the theories of psychologists Giorgi, Johnson, Koch, etc., the humanistic theory of Rogers and the ideas of the existentialism and phenomenalism philosophies [2]

\section{THE WATSON'S THEORY OF HUMAN NATURE CARE}

\section{A. Care: the Philosophy and Science of Care}

In 1979, when Watson was asked to write a nursing textbook, she published Nursing: the Philosophy and Science of Caring [3] firstly. Watson put forward a philosophy of nursing and care, thereby reducing the division in theory and practice. The philosophy of caring is the philosophical foundation of the nursing discipline. With the passage of time, cultural communication and traditional innovation, it has become more common, and it is and will be also a promising and exemplary public nursing demand for human caring, healing and health now and in the future. In the context of the science of caring, the theory of human caring and love in personal form has been evolved through the words of Watson. The philosophy and science of caring includes the foundation of the worldview of philosophy ontology, the calligraphy ontology, the ethical attribution and the scientific guidance for caring beyond the personal and nursing caring. Nursing: the Philosophy and Science of Caring accurately analyzes the "human nursing theory", clearly expounds the unique insights of the "human nursing" into people, health, environment and nursing, and human nursing is an art, which is not only manifested in the nurses' elegant manners, neat instruments, light movements and aesthetic feelings, but also more importantly in the true feelings of the nurses to the patients.

\section{B. Nursing: the Philosophy and Science of Care}

In 1985, Watson [4] published Nursing: Human Science and Human Care, which emphasizes that the human care is the essence and core of nursing, the individual patient should be focused, the individual patients should be respected, the individualized nursing should be given to patients according to changes in the disease conditions and different disease stages and a timely evaluation should be made on the nursing effect. It describes how the science of human care is applied to guide the clinical practice of nursing, which must be completed by the nursing staff in the interaction with the patients in combination with scientific and human knowledge in order to achieve the goal of nursing, i.e. to prevent the occurrence of the disease, care for the patients, make patients cured or promote patients' health. Watson [5] believes that the relationship between people explains the secrets of human nature and the greater power, order, or energy that can be stimulated in the universe through nursing procedures, which can stimulate the healing process and health and promote the self-healing in turn. Watson's human care theory has the same origin as the holistic nursing [6] and it is an extension of the holistic nursing. It has overcome the shortcomings of the traditional nursing mode, pays more attention to physical and psychological nursing while pays attention to operational activities, and advocates providing patients with a sincere, trustful and psychologically supportive medical environment [7]. 


\section{Watson's Top Ten Humanity Process [8]:}

Form a humanity - altruistic value system. A humanity altruistic value system will be formed to the nurses by their understandings on one's views and beliefs, communications, cultural interactions and contacts with patients under different backgrounds as well as self-growth experiences. Therefore, through presentation and exhibition, the nurses can also feel satisfied, realize their life values and provide better assistance for others.

Ndoctrinate confidence and hope by nurses to patients in nursing practice. Nurses should assist patients in seeking healthy behaviors, positive encouragement and support and effectively establish a trust relationship with patients in order to achieve the goal of promoting rehabilitation, which is necessary for nursing and treatment processes.

Cultivate sensitivity to self and others. Nurses can selfaccept the values and beliefs in order to self-achieve the goal of life values, express their own feelings in order to better help patients express their feelings, find the internal pathogenic factors and solve the problems.

Develop a help-trusted relation. I.e. establish a good relationship between nurses and patients. This relationship includes: consistency (there is an equal and mutually supportive relationship between nurses and patients) is reached for the patients' health, i.e., the nurses should deal with problems from the perspective of patients, care about patients' inner feelings and maintain patients' dignity and behavior though effective exchange and communication and other skills.

Promote and accept the expression of positive and negative feelings. Nurses should share the feelings with service objects in order to experience the importance of true feelings in the world.

Make decisions by nurses with systematic and scientific problem-solving methods. Nurses should make best care decisions in the nursing process for patients' choice and help patients to recover their self-care abilities based on the principle and concept of applying science when solving problems.

Enhance the interactive relationship between interpersonal teaching and learning. The health education can enhance the medical knowledge of the service objects, provide the self-care abilities to them and determine their personal demands in order to achieve the purpose of the internal balance self-recovery.

Provide supportive, protective and corrective psychological, physiological, socio-cultural and spiritual environment. The adaptability of the service objects should be assessed and enhanced in order to support, protect and correct their physical and mental health and provide a comfort, quiet, clean and private environment.

Provide assistance in meeting people's needs, both of the nursing staff and service objects have various needs for the body, mind, society and individual, and the high-level needs can only be met after the low-level needs are met. The nurses should help the service objects to meet various needs.
Understanding the needs of the service objects The nursing staff can understand themselves and others more easily and provide effective professional services to the service objects by evaluating the life experience of the service objects with the epidemiological principles and methods, understanding the service objects' perspective on health, disease and lifestyle and making them know the fact that it is very important for their health.

\section{THE APPLICATION STATUS OF WATSON'S THEORY OF HuMAN NATURE CARE AT HOME AND ABROAD}

\section{A. Its Application Status at Abroad}

The human care and nursing services, which started earlier, have been developed very well in practice and theory. Existing research shows [9] human care and nursing theory is an existing theory in human relations, which guides the understanding of nursing and the practice of morality and protects people's dignity throughout life. Existing foreign researches find [10-11] the application of human care theory in nursing practice can make the exchange between the nurses and patients more sincere, enhance their communication and establish a harmonious relationship between nurses and patients. In terms of the application of Watson's theory, the most famous event in nursing practice is the "Denver Nursing Project in Human Caring", which was launched in 1988 in the Human Care Center in Denver, Colorado. Ozkan et al [12]'s nursing based on Watson's human care theory played an important role in improving patients' psychological problems in the example of an infecund woman from Turkey. Foreign researches show [13] that the psychological state of the family members' anxiety can be alleviated if the nursing intervention is carried out for the family members of critically ill patients under the guidance of the human care theory. Norman et al.'s [14] researches find that the nurses will be more willing to discuss and apply human care in their daily work if a caring environment is created for nurses and patients and the nurses are promoted to understand the caring theory through experiential teaching. In the past period of time, caring science has not only changed the nursing, but also has raised the importance to people's dignity and ethics in the process of nurse education practice and career development.

\section{B. Its Application Status at Home}

The human care in China, which started relatively late, is mainly based on the reference to foreign theories, but in recent years, it has become more and more widely used in clinical practice. In the 21 st century, especially after China's accession to WTO, China's nursing industry is facing major reforms. Because of its practicality, feasibility, importance and significance, the human care theory has been widely promoted in clinical nursing work, and the application of Watson's human care theory in clinical nursing practice can improve the quality of nursing and promote the rehabilitation of patients. The research results of DANG Jin et al. [15] show that the modern medical mode, which is based on the "people"- oriented nursing, not only pays attention to the disease itself, but also meets the demands for patients' psychological nursing and returning to society under the support of Watson's caring 
theory. MA Fang et al. [16]'s research results show that: Watson's caring theory, which is people-oriented, emphasizes the adherence to human beliefs and respects for the individuality of patients, has a good effect on integrating patients with chronic diseases into normal life and improving the quality of their lives. LIN Shuang et al. [17]'s research results show that Watson's caring theory will create a more effective treatment method and a safer and more comfortable nursing environment for patients with Alzheimer's disease, therefore, the patients can get faster recovery and higher quality of life, and Watson's caring theory can also significantly reduce the disease index of patients with Alzheimer's disease. Watson's caring theory is a continuous and systematic process, which provides good assistance in developing a more standardized and more effective AD patient nursing program. SUN Yan [18]'s investigation and research shows that the pregnant women with threatened abortion often have serious psychological problems, and Watson's human caring theory can strengthen the human nursing of patients, thereby effectively alleviating the psychological problems of patients. PENG Cuie et al [19] has applied human caring to a patient with postoperative breast cancer, they provided nursing for patients focusing on the patient's subjective experience and inner world and in combination with scientific and human knowledge. Through experiments, HE Rongfang et al. [20] find that the nursing measures based on Watson's human caring theory have a significant effect on alleviating the tension and anxiety of patients. KE Liqing [21] has developed specific nursing measures based on Watson's top ten care factors, she has nursed an orphan with hypospadias during perioperative period, and the results show that the fear of children was alleviated. DING Lanhua [22] has developed caring propaganda and education contents for parents, and the results show that the effective rate of parents' acceptance of health education is $93 \%$, with an increase of $8 \%$ over the same period in 2013. ZHENG Lianxue et al. [23] find that the results will be satisfactory if adopting human care concept during the provision of nursing services according to Watson's caring theory, using empathy method, discovering and considering problems from the perspective of patients, paying close attention to patients' inner activities and assisting patients in establishing positive and healthy positive and negative emotional expression methods and strictly maintaining the patients' dignity. It can be seen that the nursing based on Watson's human care theory can effectively improve the patients' satisfaction and the quality of life of patients.

At present, Watson's human care theory has been highly concerned and has become a hot topic in clinical research. It is people-oriented, emphasizes adherence to people's beliefs, respects for the individuality of patients, emphasizes the human care process such as communication skills, interpersonal interactions and cares for nurses and patients, therefore, the health and rehabilitation can be promoted. It not only provides a framework for caring nursing, but also provides a meaningful ethical and conceptual foundation for nursing practice. In the field of clinical nursing, human care theory has been confirmed in different places and different nursing objects.

\section{REFERENCES}

[1] Watson J. Nursing: the philosophy and science of caring [M]. Boston: Little, Brown and Company, 1979.245.

[2] Editors in Chief: HUANG Xingzhi, LIU Yilan and YANG Chun. Science of Caring Nursing: Application of Watson' s Human Caring Theory in Nursing [M]. Beijing: Military Science Publishing House, 2009:3.

[3] Watson J. Nursing: the philosophy and science of caring [M]. Boston: Little, Brown and Company, 1979.245.

[4] Watson J. Nursing: human science and human care-a theory of nursing [M]. Jones and Bartlett Publishers Inc,1999.

[5] Watson J. Nursing: Human Science and Human Care[M].New York: National League for Nursing,1985:1-3.

[6] Watson J. Nursing: human science and human care-a theory of nursing [M]. Jones and Bartlett Publishers Inc,1999.

[7] Xiaoou ZHANG. The Role of Human Nursing in Holistic Nursing [J]. China Practical Medical 2010.10(5):240-241.

[8] An li JIANG Nursing Theories [M]. Beijing: People's Medical Publishing House, 2009: 226-240.

[9] Rosa W1,Estes T2, Watson J3.Caring Science Conscious Dying: An Emerging Metaparadigm [J]. Nurs Sci Q,2017,30(1):58-64.

[10] Brewer BB, Watson J. Evaluation of Authentic Human Caring Professional Practices [J]. J Nurs Adm,2015, 45(12):622-627.

[11] Persky GJ1,Nelson JW, Watson J, et al. Creating a profile of a nurse effective in caring [J]. Nurs Adm Q,2008,32(1):15-20.

[12] Ozkan IA, Okumus H, Buldukoglu K.A case study based on Watson' s theory of human caring: being an infertile woman in Turkey[J]. Nurs Sci Q,2013 Oct;26(4):352-9.

[13] Vazquez Calatayud M,Eseverri Azcoiti MC.The caring of family members in the intensive care units from the Jean Watson perspective[J].Enferm Intensiva,2010 21(4):161-164.

[14] Norman V, Rossillo K, Skelton K.Creating Healing Environments Through the Theory of Caring[J]. AORN J,2016,104(5):401-409.

[15] Jin DANG and Zhongying SHI. Analysis of the Application Effect of Watson' s Caring Theory in the Rehabilitation of Elderly Patients with Schizophrenia [J]. Journal of Chinese Physician, 2013, 15(8): 1080-1082.

[16] Fang MA and Jianhua SONG. Application and Exploration of Watson' s Caring Theory in the Nursing of Patients with Chronic Diseases [J]. Medicine and Philosophy, 2008, 29(18): 75-76.

[17] Shuang LIN, Ying ZHANG, HAN Jing, et al. Application of Watson Caring Theory in Nursing for Elderly Patients with Alzheimer's Disease [J]. Progress in Modern Biomedicine, 2015,15(18):3558-3560.

[18] Yan SUN. Application of Watson's Human Care Theory in a Pregnant Woman with Threatened Abortion [J]. Special Health, 2017 13:202 -203.

[19] Cuie PENG, Zan LI, ZHOU Bo, LV Chunliu, ZHOU Yanwu, PENG Xiaowei and SONG Dajiang. Application of Watson Care Theory in Nursing of Patients with Breast Wall Ulceration after Breast Cancer Surgery [J]. Journal of Nurses Training, 2017,32 (18) :1666-1668.

[20] Rongfang HE, Qiyan ZHONG, GU Qingyan, et al. Evaluation on the Effects of Watson's Human Care Theory on Improving the Psychological State of AIDS Patients [J]. Medical Information, 2016, 29(19): 107-108.

[21] Liqing KE. Application of Watson's Human Care Theory in Nursing of a Case of an Orphan with Hypospadias during Perioperative Period [J]. Chinese Journal of Practical Nursing, 2014, (2): 42-43.

[22] Lanhua DING. Application of Watson's Human Care Theory in Pediatric Health Education [J]. Bio-IT World, 2015, (6): 225-226.

[23] Lianxue ZHENG, application of Watson's Caring Theory in AIDS Clinical Nursing [J]. Chinese Journal of Modern Nursing, 2012, 18 (10): 1131-1134. 